\title{
Fórum como estratégia para o engajamento na disciplina de Geometria Plana: análise de uma experiência em Ensino Remoto
}

Márcia Rodrigues Notare, PPGIE/UFRGS, marcia.notare@ ufrgs.br, 0000-0002-2897-8348

Renata Cezar Pinto, PPGIE/UFRGS, rehpinto@ hotmail.com, 0000-0002-0058-0071

Resumo: Este artigo apresenta uma investigação sobre os impactos do engajamento e das interações sociais na aprendizagem de Geometria Euclidiana Plana, em atividades realizadas em fóruns no ambiente virtual de aprendizagem institucional, durante o Ensino Remoto Emergencial. Trata-se de uma pesquisa qualitativa com o objetivo de identificar evidências de desenvolvimento do pensamento geométrico e da habilidade de argumentação, além da apropriação dos recursos do software GeoGebra para apoiar a argumentação nos fóruns de discussão colaborativa disponibilizados ao longo do desenvolvimento da disciplina. Os resultados da pesquisa mostram que o engajamento nos fóruns teve impacto positivo nas construções geométricas realizadas no GeoGebra e na qualidade das demonstrações geométricas.

Palavras-chave: GeoGebra, geometria euclidiana, fórum colaborativo, ensino remoto.

\section{Forum as an engagement strategy in the discipline of Plane Geometry: analysis of an experience in Remote Learning}

Abstract: This article presents an investigation on the impacts of engagement and social interactions on Plane Euclidean Geometry learning, in activities carried out in forums in the virtual institutional learning environment, during Emergency Remote Teaching. This is a qualitative research with the objective of identifying evidences of the development of geometric thinking and argumentation skills, in addition to the appropriation of GeoGebra software resources to support argumentation in the collaborative discussion forums made available throughout the course's development. The survey results show that the engagement in the forums had a positive impact on the geometric constructions carried out in GeoGebra and on the quality of the geometric beads.

Keywords: GeoGebra, euclidean geometry, collaborative forum, remote learning.

\section{Introdução}

Em 2021, o ano letivo permaneceu na modalidade de Ensino Remoto Emergencial (ERE), devido à Pandemia COVID 19. Nesse período uma nova turma de Licenciatura em Matemática ingressa na Universidade Federal do Rio Grande do Sul (UFRGS) e o desafio é acolher os novos acadêmicos durante o desenvolvimento da disciplina de Geometria Plana e promover a habilidade de argumentação geométrica.

No ERE a conduta do professor e as estratégias pedagógicas precisam ser diferentes do modelo presencial ou do modelo de Educação a Distância $(\mathrm{EaD})$, visto que esses alunos estão esperando um curso presencial, embora estejam inseridos em um Ambiente Virtual de Aprendizagem, nesse caso o Modular Object-Oriented Dynamic Learning Environment (MOODLE), não dispõem dos espaços físicos da universidade, nem dos encontros presenciais com colegas e professores. Nesse sentido, buscou-se utilizar estratégias e recursos que oportunizassem a interação entre alunos e professores em momentos síncronos e assíncronos, aproximando-os e engajando-os em seu processo de aprendizagem de maneira ativa e colaborativa.

No presente artigo, investigamos "Como as interações nos fóruns podem contribuir com a aprendizagem colaborativa de Geometria Plana e para o desenvolvimento da argumentação 
em Geometria?", ancorados em dois pilares que entendemos ser fundamentais nesse processo: a interação social e colaboração e os ambientes de geometria dinâmica.

\title{
2. Interação Social e Colaboração no Processo de Aprendizagem
}

Em situações de ensino em modalidade remota, como a que ainda estamos vivendo em algumas instituições de ensino, o processo de aprendizagem não pode ser passivo. O engajamento dos estudantes em interações sociais virtuais e no comprometimento na realização das tarefas é fundamental, pois aprender é um processo ativo. Assim, a aprendizagem na modalidade ERE torna-se um processo dinâmico e complexo, que desafiou e vem desafiando professores de todos os níveis de ensino.

O papel dos estudantes nesse processo exige contribuições que vão desde o envio de mensagens que comuniquem pensamentos e ideias, até a construção colaborativa de conceitos, formada por uma rede de aprendizagem na qual as interações entre os pares constituem a base para a construção do conhecimento. Neste sentido, avaliar a aprendizagem destes alunos envolve, também, compreender a profundidade do conhecimento produzido e as novas competências que foram desenvolvidas nestes espaços (Araújo e Lucena, 2005).

Papert (1980) afirma que "Falar Matematicamente" é mais facilmente aprendido quando se pode compartilhar e discutir experiências ricas em matemática dentro de uma comunidade de apoio ao discurso matemático. Stahl (2009) destaca a importância da comunicação de novas aprendizagens para a efetiva consolidação cognitiva

\begin{abstract}
... alguém pode aprender algo um dia e dar sentido a isso mais tarde, quando tentar usar em diferentes circunstâncias e para explicar seu uso a outras pessoas e a eles próprios. Mas se eles nunca integram o que aprenderam em seu próprio pensamento e ação - aplicando-o quando apropriado e falando sobre isso com clareza, então eles não terão aprendido nada importante. (Stahl, 2009, p.01)
\end{abstract}

É evidente que nem todas interações têm a mesma contribuição para o processo de aprendizagem nos fóruns de discussão. Araújo e Lucena (2005) apontaram os seguintes critérios para classificar as interações em fóruns: (1) Não contribui para a discussão em pauta; (2) Resposta à pergunta feita pelo professor; (3) Postura questionadora, que propõe dilemas, apresenta alternativas e pede posicionamentos; (4) Postura debatedora, que comenta contribuições anteriores, responde a questionamento de outro colega ou apresenta contraargumento; (5) Postura sintetizadora, que coleta segmentos da discussão e elabora parecer conclusivo.

Assim, oferecer oportunidades para que os estudantes possam se envolver em interações com colegas pode contribuir para a aprendizagem remota. Para Stahl (2009), ao articular o pensamento e a aprendizagem em textos, os estudantes tornam a cognição pública e visível. Para isso, é necessário que os docentes utilizem estratégias para facilitar a prática de diálogo entre os alunos, articulando conteúdo matemático e recursos para apoiar e orientar o discurso estabelecido entre eles. Em período de ERE e início de curso, foi fundamental pensar em estratégias que permitissem aos acadêmicos ter a sensação de pertencimento de grupo e, ao mesmo tempo, conduzirem suas próprias aprendizagens de maneira ativa e autônoma.

\section{GeoGebra e as Demonstrações Geométricas}

A disciplina de Geometria Plana do curso de Licenciatura em Matemática da UFRGS defende como atividade cognitiva fundamental explorar com os estudantes as potencialidades do ambiente de geometria dinâmica GeoGebra para a aprendizagem de Geometria Euclidiana Plana, por meio da realização de construções geométricas estáveis e dinâmicas, experimentações e investigações ativas que desencadeiem a formulação de conjecturas e demonstrações geométricas de propriedades e teoremas. Isto porque, para esta área da Matemática, argumentação e prova são fundamentais para a compreensão de teoremas e 
propriedades que constituem a essência axiomática-dedutiva da Geometria Euclidiana (Notare e Basso, 2018).

As figuras geométricas construídas nestes ambientes, quando apoiadas em propriedades e estáveis sob a ação do arrastar, impõem uma lógica intrínseca e crucial, que colocam os elementos geométricos da construção em hierarquia de propriedades, implicando na hierarquia de escolha das ferramentas do ambiente e, portanto, revelando um encadeamento lógico que pode dar suporte ao processo de argumentação e prova (Arzarello et al, 2012). A ação de arrastar permite identificar propriedades e regularidades que permanecem estáveis na multiplicidade de configurações que surgem continuamente na tela.

Conforme Stahl (2015, p.40) "o uso de um ambiente de geometria dinâmica pode ajudar a mover os alunos desde os estágios iniciais destas sequências (reconhecimento e comunicação) para os níveis avançados (dedução e sistematização).”. O que pode ser potencializado quando essas explorações são realizadas em colaboração com seus pares, no qual os alunos são orientados a refletir e discutir sobre as construções geométricas a partir das propriedades que as definem.

\section{Geometria Plana: Estratégias para o ERE}

Ancorados pelos dois pilares fundamentais para a aprendizagem de Geometria em modalidade de ensino remoto, apresentados nas seções anteriores - interação social e colaboração e ambiente de geometria dinâmica - a disciplina foi organizada no ambiente MOODLE, articulando ações semanais que desencadeassem engajamento no processo de desenvolvimento do pensamento geométrico de maneira colaborativa e sempre impulsionando o processo de construções geométricas estáveis no GeoGebra e a demonstração de propriedades e teoremas presentes nestas construções.

Assim, como estratégia pedagógica para proporcionar envolvimento e rotina de estudos aos novos acadêmicos, estabeleceu-se uma organização semanal, na qual eram disponibilizados variados recursos como: vídeoaulas expositivas, abordando conteúdos teóricos que inserem os estudantes no universo das demonstrações geométricas; arquivos teóricos complementares em PDF ou materiais disponibilizados na internet; applets de manipulação dinâmica; atividades com entregas semanais, sempre envolvendo construções geométricas no GeoGebra e demonstrações geométricas; fórum de dúvidas semanais. As estratégias foram pensadas de modo a conduzir os estudantes desde estágios iniciais do processo de argumentação em Geometria, que passam por níveis de reconhecimento e identificação de propriedades e comunicação e expressão das mesmas, até níveis avançados de dedução e sistematização, que evidenciam encadeamento lógico-dedutivo (Stahl, 2015). As atividades foram cuidadosamente elaboradas para introduzir os alunos no universo das construções geométricas dinâmicas, que colocam os elementos geométricos em uma hierarquia de propriedades (Arzarello, 2012), favorecendo a organização de ideias e conduzindo às demonstrações.

Além destes recursos, para impulsionar os processos de interação social e colaboração entre os estudantes, foram elaborados fóruns colaborativos semanais, cujo objetivo foi proporcionar um espaço para o compartilhamento das construções e demonstrações, e incentivar as trocas colaborativas a partir da estratégia de promover postagens com comentários sobre as resoluções dos colegas, convidando os estudantes a participar de uma comunidade de construção coletiva de discurso geométrico. Finalmente, além destas estratégias pedagógicas assíncronas, uma vez por semana foi planejado um encontro síncrono, não obrigatório, no qual os estudantes tinham a oportunidade de tirar dúvidas, debater sobre as tarefas em andamento e interagir com o docente e com os demais colegas da turma. Neste artigo, vamos analisar, em particular, o impacto do fórum colaborativo no processo de engajamento e aprendizagem dos estudantes. 


\section{Fórum Colaborativo: incentivando engajamento e colaboração}

O recurso fórum disponibilizado pelo MOODLE apresenta várias potencialidades para professores e alunos, favorecendo a interação social e o engajamento, constituindo-se em um espaço no qual os envolvidos na disciplina podem debater sobre conteúdos e atividades e compartilhar materiais diversos (vídeos, imagens, links, textos etc.). Vamos analisar nesta seção episódios ocorridos no Fórum Colaborativo, nos quais foi possível identificar o engajamento dos acadêmicos para a construção coletiva de conhecimento geométrico. Nos Fóruns Colaborativos semanais, os alunos foram incentivados a postar resoluções para os problemas ${ }^{1}$ indicados na semana, que abordavam demonstrações geométricas, além de analisar e comentar as argumentações elaboradas pelos colegas. Neste processo, os alunos tiveram a oportunidade de interagir e contribuir para a aprendizagem do grupo e para o desenvolvimento da habilidade de argumentação. Como os fóruns permitem discussões assíncronas, essas interações ocorriam ao longo da semana, onde cada estudante participava no seu tempo. Estas atividades foram pensadas como estratégia para proporcionar aproximação entre os estudantes, dando a oportunidade para que se sentissem pertencentes ao grupo e que essa presença social pudesse impactar na construção do conhecimento individual e coletivo, culminando na evolução do discurso e no desenvolvimento do pensamento geométrico. Como recorte de uma análise mais ampla, vamos analisar as contribuições de um aluno, denominado A1, e sua rede de interação. As análises estão organizadas em sequência cronológica a seguir, abordando algumas interações de A1 no percurso da disciplina.

\subsection{Fórum - Segmento de Reta}

O primeiro fórum colaborativo propôs cinco problemas envolvendo demonstrações sobre segmentos de retas. Os alunos foram orientados a: (1) escolher um dos problemas para resolver e compartilhar; (2) escolher a resolução de um colega para analisar e comentar.

O A1 resolveu o seguinte problema:

Sejam quatro pontos $A, B, C, D$ dispostos sobre uma reta, nessa ordem, e tais que $\overline{A C}$ e $\overline{B D}$ sejam congruentes. Demonstre que os segmentos $\overline{A B}$ e $\overline{C D}$ são congruentes e que os segmentos $\overline{B C}$ e $\overline{A D}$ têm o mesmo ponto médio.

Sua demonstração foi organizada conforme extrato abaixo:

Para provar que os pontos médios de $B C$ e $A D$ são coincidentes, foi imposto que $B C$ possui medida $y$ e que $A B$ e $C D$ (que são congruentes) possuem medida $x$ cada um.

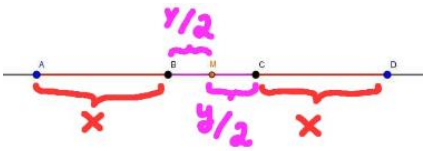

Logo, o ponto médio $M$ de $A D$ se encontrará à distância de $(2 \mathbf{x}+\mathbf{y}) / \mathbf{2}=\mathbf{x}+\mathbf{y} / \mathbf{2}$, tanto de $A$ quanto de $D$.

Pode-se observar que $\mathbf{x}+\mathbf{y} / \mathbf{2}$ se trata do comprimento de $A B$ e $C D(x)$ com a adição da metade do comprimento de $B C(y / 2)$, que o divide em duas partes iguais de forma que o ponto médio $M$ de $A D$ também será o ponto médio de $B C$. Portanto os dois segmentos compartilham do mesmo ponto médio.

Percebe-se que A1 procurou articular sua argumentação com imagens de segmentos de retas construídos no GeoGebra, recurso no qual comentou durante o encontro síncrono da primeira semana, não ter familiaridade. Apesar disso, A1 apresentou aos colegas um discurso geométrico apropriado, apoiado pelos recursos que tinha domínio, conforme pode-se identificar na sua resolução, que integra texto, print da tela do GeoGebra com edição da imagem para destacar os elementos geométricos pertinentes para sua argumentação.

Para contemplar a segunda parte da tarefa, A1 contribuiu na resolução de A2 (Figura 1), que apresentou solução para o problema enunciado a seguir:

\footnotetext{
${ }^{1}$ Os problemas propostos no fórum colaborativo foram retirados de Dolce e Pompeo (2005), bibliografia básica da disciplina.
} 
Sejam quatro pontos $A, B, C, D$ dispostos sobre uma reta $r$, nessa ordem, e tais que $\overline{A B}$ e $\overline{C D}$ sejam congruentes. Demonstre que $\overline{A D}$ e $\overline{B C}$ têm o mesmo ponto médio.

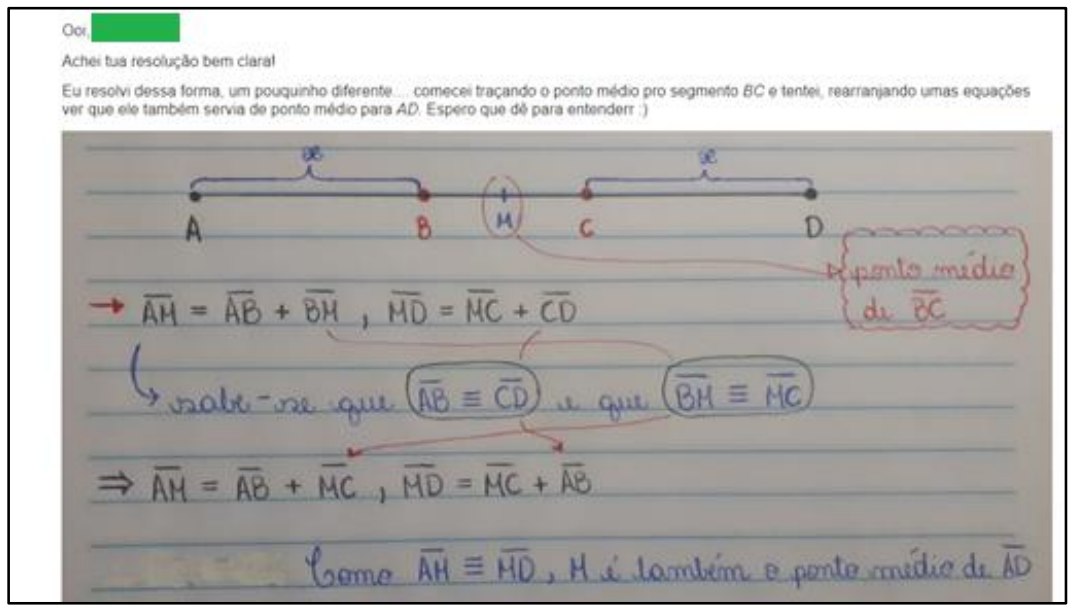

Figura 1 - Contribuição de A1 na resolução de A2.

Fonte - Captura de tela no MOODLE.

Observa-se que A1 trouxe contribuições importantes com seu comentário, apresentando alternativas de resolução para o problema, ampliando o debate para a construção do conhecimento coletivo e contribuindo para a discussão em pauta. Por outro lado, na sua resolução, recebeu o comentário de A3, que se limitou a elogiar "Gostei dos seus metodos de passo a passo, deu para entender direito a resolução da questão 3”. Identificamos neste comentário que A3 não trouxe contribuições substanciais para a construção do conhecimento coletivo, caracterizando-se como uma participação que, apesar de positiva, não contribui para a discussão (Araújo e Lucena, 2006; Pereira, 2011).

\subsection{Fórum - Congruência de Triângulos}

Neste fórum foram disponibilizados dez problemas. A1 resolveu o problema descrito a seguir:

Prove que as bissetrizes relativas aos lados congruentes de um triângulo isósceles são congruentes.

Para resolver o problema, além de apresentar um passo a passo de sua resolução apoiado por figuras obtidas de sua construção no GeoGebra, A1 anexou o arquivo construído por ele (Figura 2), ampliando as possibilidades de acesso e manipulação aos colegas.

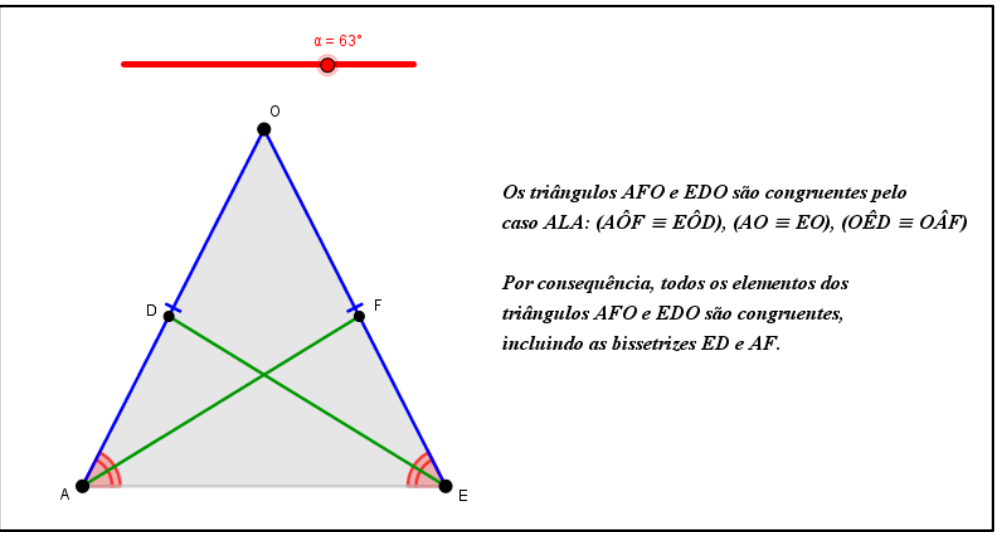

Figura 2 - Construção das bissetrizes em triângulo isósceles. Fonte - Arquivo GeoGebra construído por A1.

Destacam-se nesta postagem avanços, se compararmos com os recursos utilizados nas postagens anteriores. Aqui, A1 utiliza o controle deslizante e cores, o que revela o processo de 
apropriação do GeoGebra por A1 e o seu engajamento em apresentar uma contribuição qualificada para os colegas no fórum. O controle deslizante possibilita visualizar uma multiplicidade de configurações dinâmicas para a família de triângulos isósceles, auxiliando na identificação das propriedades pertinentes para a demonstração do teorema. Além disso, a postagem revela também avanços na habilidade de argumentação, pois A1 apresenta uma demonstração com perfeito encadeamento lógico-dedutivo. Nesta semana, não houve comentários dos colegas em sua postagem. Mas A1 postou seu comentário (Figura 3) na resolução de A4, cujo enunciado está a seguir:

Prove que, se a bissetriz relativa a um lado de um triângulo é também mediana relativa a esse lado, então esse triângulo é isósceles.

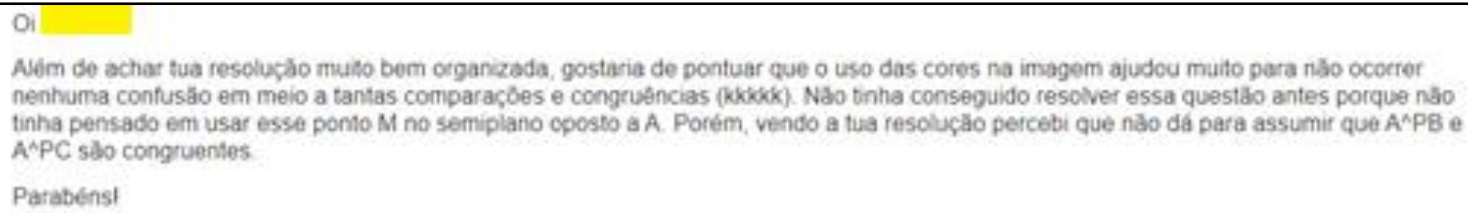

Figura 3 - Comentário de A1 na resolução de A4.

Fonte - Captura da tela do MOODLE.

O comentário de A1 traz evidências de que ele analisou a resolução do colega, buscando compreender seus argumentos geométricos e estabelecendo comparações com a sua estratégia de resolução, trazendo novamente contribuições para o debate em pauta. A partir da análise da solução do colega, A1 retoma sua argumentação e avança na solução, reforçando o fato de que a colaboração no fórum pode contribuir para a aprendizagem dos estudantes. Neste episódio, identificamos que A1 assume uma postura debatedora e sistematizadora, isto é, que dá segmento aos comentários anteriores dos colegas com propriedade, além de propor alternativas para sua própria resolução (Araújo e Lucena, 2005).

\subsection{Fórum - Perpendicularidade}

Este fórum propôs a discussão de sete problemas. A1 resolveu o problema enunciado a seguir:

$$
\text { Demonstre que em todo triângulo isósceles sempre temos duas alturas congruentes. }
$$

Neste fórum, A1 postou o arquivo construído no GeoGebra, no qual incorporou, de maneira organizada, dinâmica e interativa, os passos de sua argumentação, conforme Figura 4.

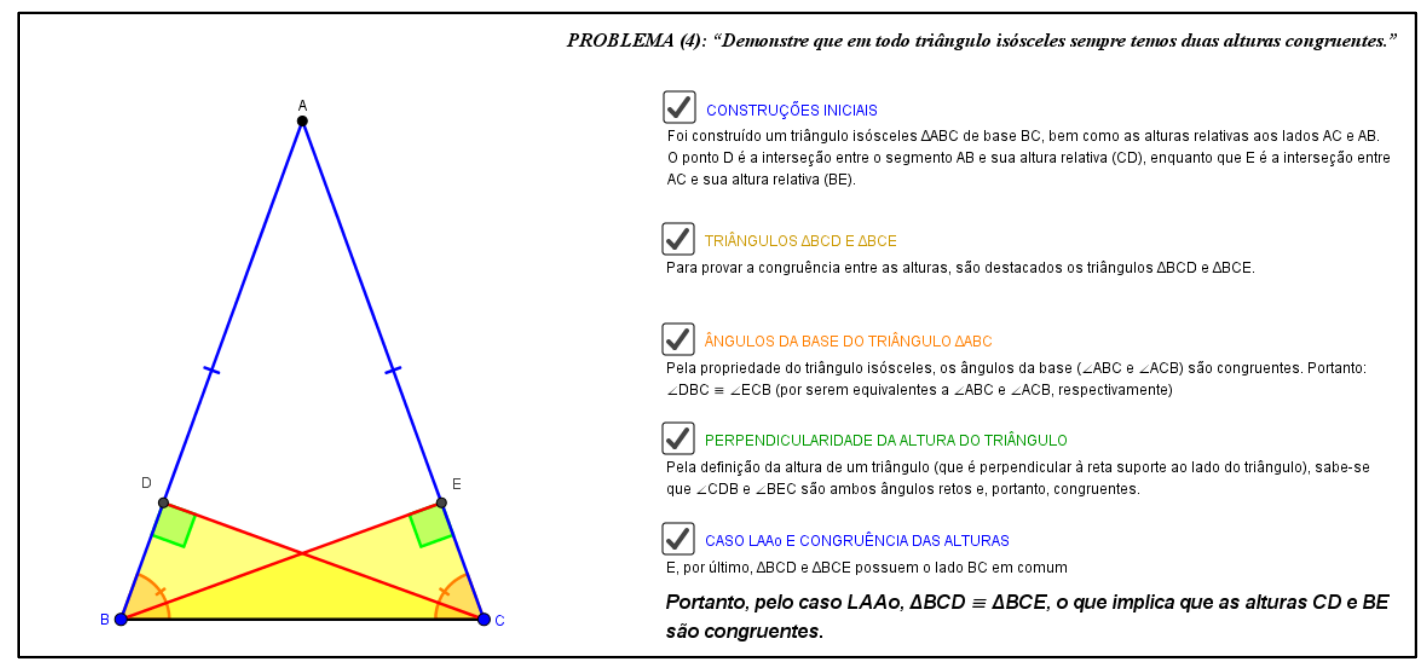

Figura 4 - Construção das alturas congruentes em um triângulo isósceles.

Fonte - Arquivo GeoGebra construído por A1. 
Destaca-se a apropriação cada vez mais avançada dos recursos do GeoGebra por A1. Nesta postagem, além da construção geométrica e da demonstração discursiva, ele utiliza-se do recurso "Caixa para Exibir/Esconder objeto" para organizar em uma sequência lógica de argumentações as caixas de texto com os passos da demonstração, mobilizando simultaneamente figura e texto, tornando a demonstração dinâmica e bem argumentada, habilidade fundamental em um curso de Geometria para licenciandos em Matemática. O empenho de A1 foi reconhecido pelos colegas, conforme comentário de A2: "Gostei muito da sequência lógica bem didática da sua demonstração e de como usou as caixinhas de exibir/esconder pra ajudar nisso.".

Para atender à segunda parte da tarefa, A1 comentou a postagem de A5 (Figura 5), cujo enunciado foi o seguinte:

Mostre que, se uma altura e uma bissetriz de um triângulo coincidem, então este triângulo é isósceles.

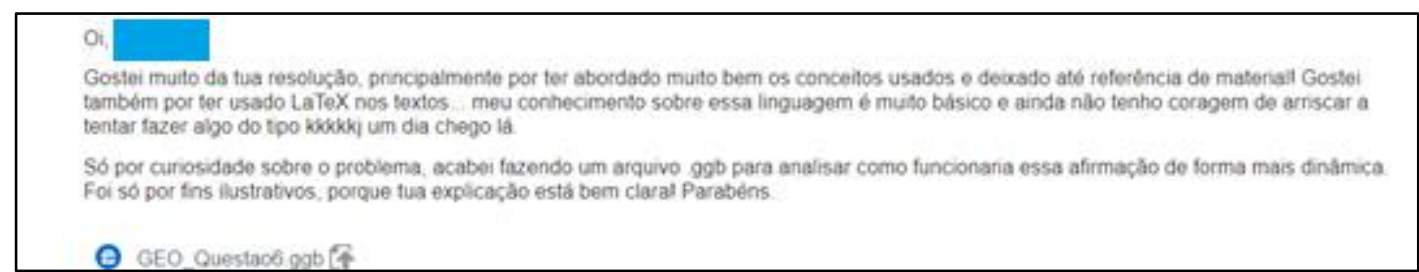

Figura 5 - Comentário de A1 na postagem de A5. Fonte - Captura da tela do MOODLE.

Nesta interação, além dos comentários pertinentes sobre a resposta do colega, A1 acrescentou um arquivo GeoGebra (Figura 6), com o objetivo de complementar e contribuir com a resolução do problema. Identificamos no comentário do A1 que a solução do colega disparou avanços no seu processo de aprendizagem, buscando suporte na construção dinâmica para analisar e ilustrar as afirmações de A5, articulando conteúdo matemático e os recursos da geometria dinâmica para apoiar os discursos estabelecidos entre eles (Stahl, 2009).

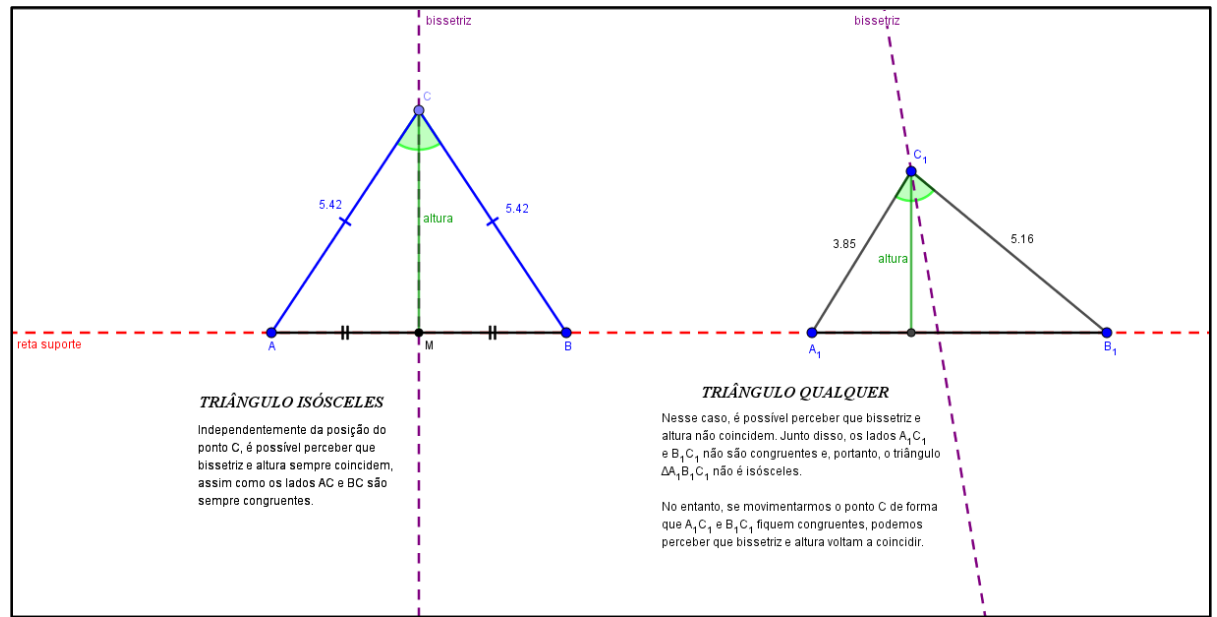

Figura 6 - Altura e bissetriz de um triângulo isósceles e de um triângulo qualquer. Fonte - Arquivo GeoGebra construído por A1.

\subsection{Fórum - Circunferência e Círculo}

Este fórum propôs doze problemas. A1 resolveu o problema com o seguinte enunciado:

Prove que qualquer paralelogramo circunscrito a uma circunferência é losango. 
Mais uma vez, A1 resolveu o problema via GeoGebra (Figura 7), evidenciado integração do ambiente de geometria dinâmica em todas as suas atividades geométricas. Nesta etapa da disciplina, percebemos que A1 já incorporou as construções geométricas estáveis e dinâmicas no processo de pensar em problemas da Geometria, impactando na elaboração de suas demonstrações geométricas.

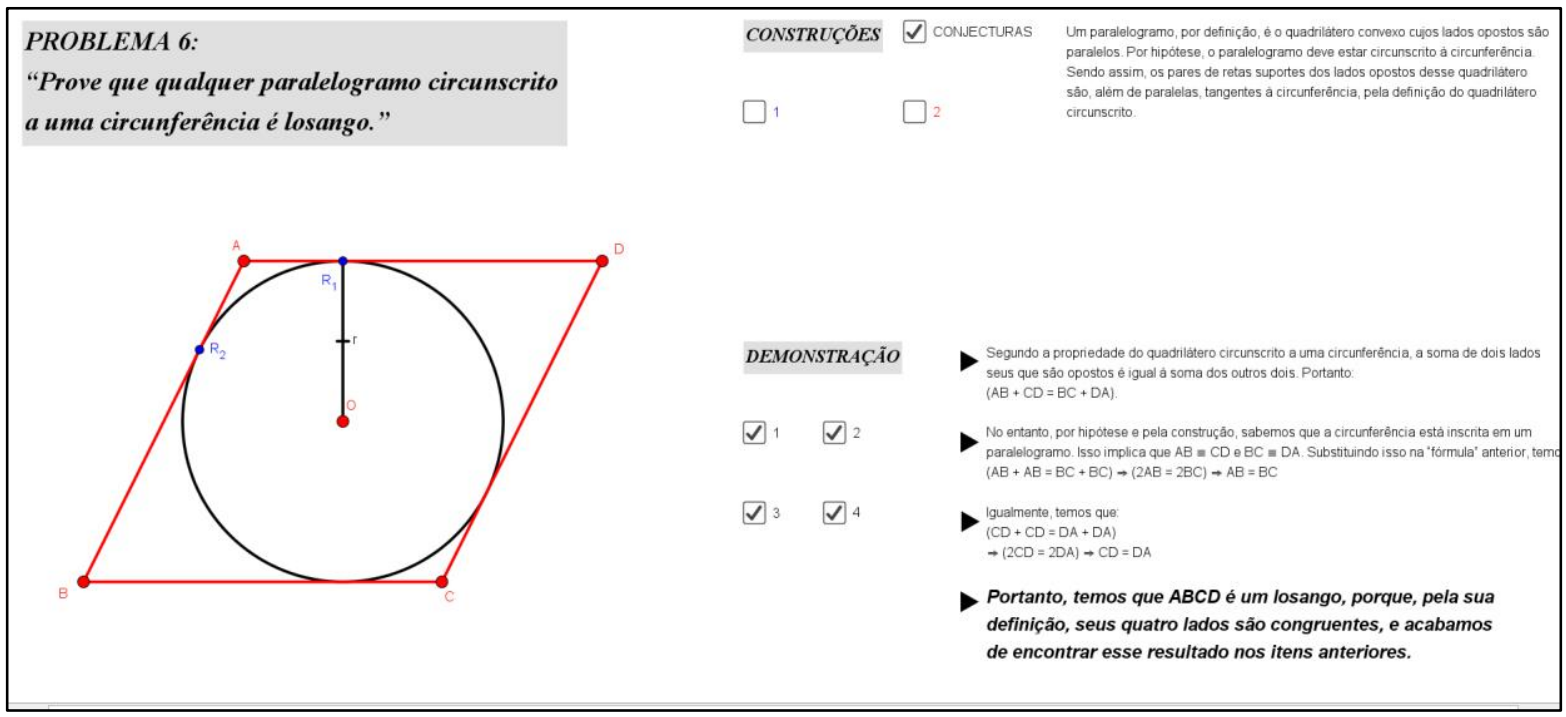

Figura 7 - Losango circunscrito a uma circunferência.

Fonte - Arquivo GeoGebra construído por A1.

Observa-se que as construções de A1 estão incorporando uma apresentação visual cada vez mais elaborada, o que evidencia apropriação da ferramenta em benefício da sua aprendizagem, e consequentemente, da aprendizagem dos colegas que acessam suas resoluções. Mais do que isso, observa-se um discurso geométrico impecável, que revela empenho e comprometimento com seu processo de aprendizagem e trazendo evidências de desenvolvimento da habilidade de argumentação em problemas cada vez mais elaborados e que exigem a identificação de um número mais elevado de propriedades geométricas.

Na segunda parte da atividade no fórum, A1 comentou a resolução de A6, que resolveu o problema enunciado a seguir:

Na figura abaixo, determine o perímetro do triângulo ADE, sabendo que o perímetro do triângulo ABC vale 10 $\mathrm{cm}$, a base $\mathrm{BC}$ mede $4 \mathrm{~cm}$ e que o círculo está inscrito no quadrilátero BCDE.

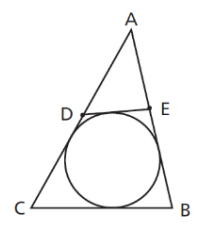

Nos comentários realizados por A1, identificamos seu potencial colaborativo, sempre atento aos detalhes das argumentações e buscando contribuir para a aprendizagem do grupo, conforme Figura 8. A1 reconhece a importância de compartilhar e discutir experiências dentro do grupo, buscando diálogo entre os colegas.

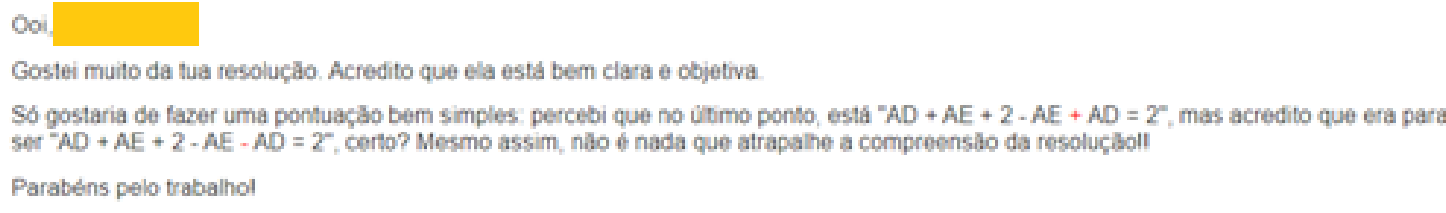

Figura 8 - Comentário de A1 na postagem de A6. Fonte - Captura da tela do MOODLE. 
As contribuições de A1 diferem das postagens de seus colegas, pois revelam a intenção de debater sobre os problemas propostos. As contribuições dos colegas, apesar de positivas, em geral, referem-se a elogios como "Achei sua sequência lógica bem didática, principalmente por você ter separado as explicações da construção e da demonstração.".

\subsection{Fórum - Teorema de Pitágoras}

Trazemos para análise este fórum, por revelar os avanços de A1 no processo de realizar demonstrações geométricas ao longo do semestre. A1 resolveu o problema enunciado a seguir:

Consideremos um triângulo retângulo $\mathrm{ABC}$, onde a medida de um ângulo agudo é $\alpha$. Determine a medida do raio da circunferência inscrita em função de $\alpha$ e da hipotenusa a.

A Figura 9 mostra sua postagem no fórum: uma construção interativa em que, ao ativar as caixas de exibir/esconder, pode-se acompanhar o desenvolvimento da argumentação.

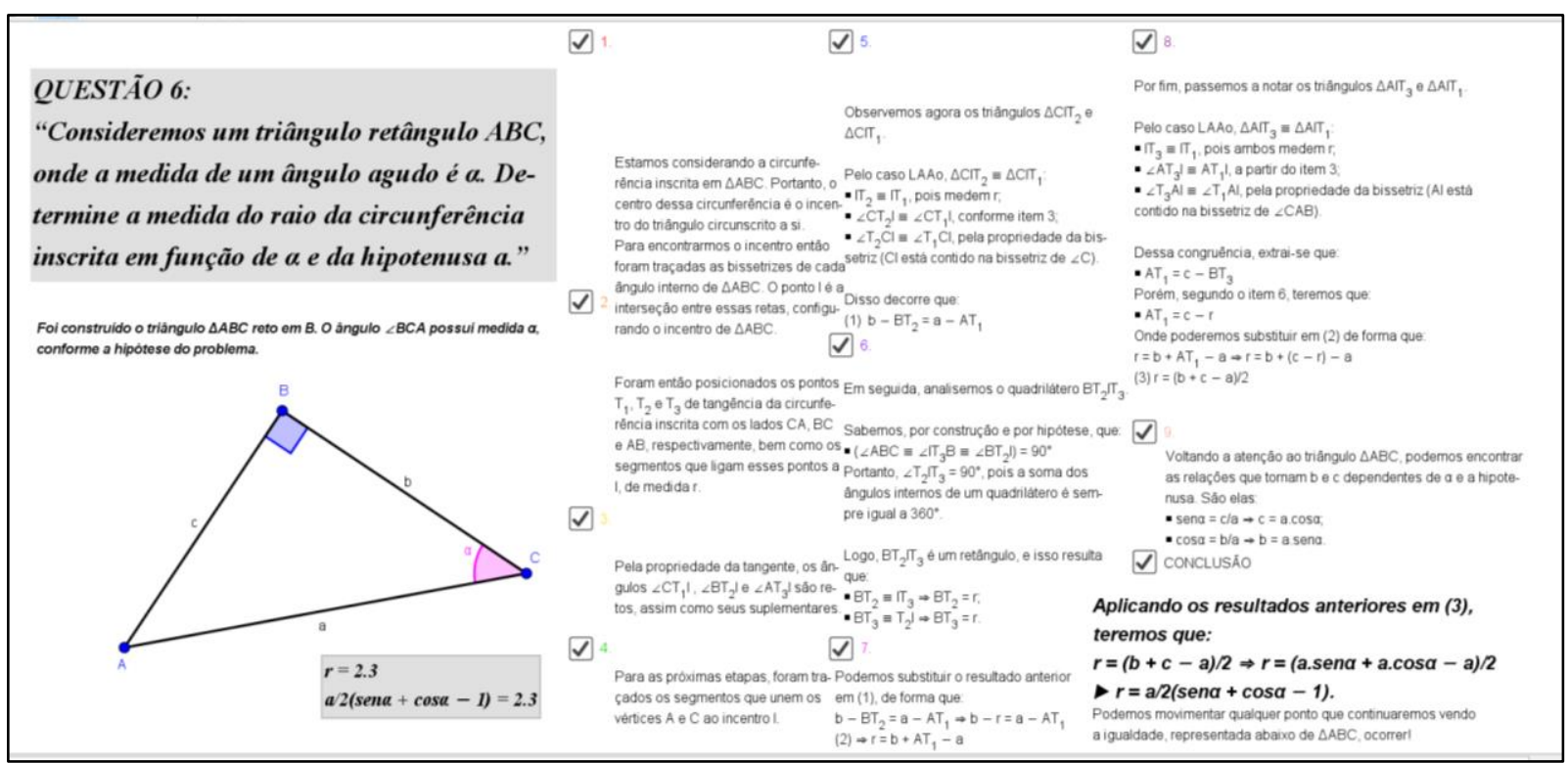

Figura 9 - Resolução apresentada por A1.

Fonte - Arquivo GeoGebra construído por A1.

Nesta resolução, além dos recursos que A1 já vinha utilizando em suas argumentações, pode-se observar o uso de símbolos LATEX disponibilizados no próprio GeoGebra. Destacamos que na quinta semana da disciplina A1 revelou ainda não ter conhecimento sobre LATEX, conforme Figura 5, na qual afirma "meu conhecimento sobre essa linguagem é muito básico e ainda não tenho coragem de arriscar em fazer algo do tipo...". O uso de símbolos apropriados apoia a argumentação, tornando o discurso geométrico cada vez mais elaborado, o que contribui para a aprendizagem de A1, bem como para a aprendizagem dos colegas que se valem dos arquivos compartilhados para compreender a resolução proposta. Essa evidência mostra o engajamento ativo de A1 na construção do conhecimento e potencial colaborador para a aprendizagem dos demais colegas.

Destacamos, ao longo das análises apresentadas, os avanços de A1 em dois aspectos: (1) apropriação dos recursos da geometria dinâmica, retomando sua manifestação na primeira semana de aula, o qual afirmou não conhecer o software e na postagem de soluções por meio de fotos em papel, até chegar a níveis de construções elaboradas e postagens exclusivas de arquivos do software; (2) desenvolvimento da argumentação e do pensamento geométrico, evidenciadas pelas questões mais elementares propostas no início da disciplina, até questões que exigiram a exploração, identificação e demonstração de sequências de propriedades e 
teoremas com encadeamento lógico-dedutivo. E acrescentamos um terceiro aspecto, que integra os dois anteriores: (3) compreensão de que construções geométricas dinâmicas no GeoGebra são fundamentais para a formulação de conjecturas e para o desenvolvimento de demonstrações geométricas. A partir de suas contribuições, fica evidenciado que A1 desenvolveu novas competências nestes espaços de interação coletiva (Araújo e Lucena, 2005).

\section{Considerações Finais}

Neste artigo, apresentamos a investigação realizada sobre o impacto das interações em fóruns na aprendizagem colaborativa de Geometria Plana e no desenvolvimento da argumentação, em uma experiência de ensino remoto emergencial. Um grupo de alunos mostrou comportamento ativo e participativo, no qual manteve suas interações, tanto no fórum, quanto nos encontros síncronos, tirando proveito de todos os espaços de interação social proporcionados pela disciplina. Analisamos o caso de um dos alunos, que se revelou engajado e comprometido com as atividades propostas, para trazer evidências dos impactos positivos daqueles que entendemos ser os pilares para o desenvolvimento da argumentação em Geometria no ensino remoto: a interação social e colaboração e o ambiente de geometria dinâmica. Entendemos que as interações virtuais tiveram impacto na construção do conhecimento geométrico, não só para aluno aqui analisado, mas para o grupo de alunos que se manteve ativo nestes espaços. As análises apontam que os discursos geométricos destes estudantes indicam aprendizagem tanto dos recursos do software, quanto da habilidade de demonstrar em Geometria e, principalmente, nas implicações de uma na outra.

\section{Agradecimento}

O presente trabalho foi realizado com apoio da Coordenação de Aperfeiçoamento de Pessoal de Nível Superior - Brasil (CAPES) - Código de Financiamento 001.

\section{Referências}

ARAÚJO, L; H. L. LUCENA FILHO, G. J. Comunidades virtuais de aprendizagem: novas dinâmicas de aprendizagem exigem novas formas de avaliação, 2005. Disponível em: http://www.nuted.ufrgs.br/oa/obj_blog/CVAsbie2005.pdf Acesso em: 22 set. 2021.

ARZARELLO, F. et al. Experimental Approaches to Theoretical Thinking: Artefacts and Proofs. In: Proof and Proving in Mathematics Education. The 19th ICMI Study. (pp. 97-137) Springer, 2012.

DOLCE, O; POMPEO, J. N. Fundamentos de matemática elementar 9: geometria plana. 8. ed. São Paulo: Atual, 2005.

NOTARE, M; BASSO, M. Argumentação e Prova Matemática com Geometria Dinâmica. Revista Novas Tecnologias na Educação, v. 16, n. 1, 2018.

PAPERT, S. Mindstorms: Children, computers and powerful ideas. New York, NY: Basic Books, 1980.

PEREIRA, S. V. M. Interação em fóruns de EAD: a otimização de um espaço de aprendizagem colaborativa, 2011. Disponível em https://periodicos.ufpe.br/revistas/EUTOMIA/article/view/1206/940 Acesso em: 22 set. 2021.

STAHL, G. How I View Learning and Thinking in CSCL Groups, 2009. Disponível em http://gerrystahl.net/pub/icce2009keynote.pdf Acesso em: 11 set. 2021.

STAHL, G. Essays in Collaborative Dynamic Geometry, 2015. Disponível em http://gerrystahl.net/elibrary/dynamic/dynamic.pdf Acesso em: 12 set. 2021. 